\title{
New Approach to Filling a Corpectomy Defect by Stacking Multiple Peek Cages around a Fibula Strut Graft: A Technical Note
}

\section{Kingsley R. Chin ${ }^{1 *}$, Fabio J.R. Pencle ${ }^{2}$, Jason A Seale ${ }^{2}$, Rishabh G. Jethanandani ${ }^{3}$, Elijah A. Hothem ${ }^{2}$ and Vanessa Cumming ${ }^{4}$}

${ }^{1}$ Charles E. Schmidt College of Medicine at Florida Atlantic University \& Less Exposure Surgical Specialists Institute (LESS Institute), 1100 W. Oakland Park Blvd. Suite \#3 Fort Lauderdale, FL, USA

${ }^{2}$ Less Exposure Surgical Specialists Institute (LESS Institute), 1100 W. Oakland Park BIvd. Suite \#3 Fort Lauderdale, FL, USA

${ }^{3}$ Charles E. Schmidt College of Medicine at Florida Atlantic University, 1100 W. Oakland Park Blvd. Suite \#3 Fort Lauderdale, FL, USA

${ }^{4}$ Society of Facet Surgical Techniques and Technologies Inc., LES Society, 300 E. Oakland Park Blvd. Suite 502, Wilton Manors, FL, 33334, USA

\begin{abstract}
Study background: Fibula strut grafts alone during anterior cervical corpectomies have some inherent vulnerability. In contrast PEEK (Polyetheretherketone) cages are more stable but need separate graft material for interbody fusion. The opportunity therefore exists to combine the positive attributes of a fibula strut graft and a PEEK interbody cage for corpectomy. The authors aim to illustrate the use of stacking multiple PEEK cages around a fibula strut graft for cervical corpectomy.
\end{abstract}

Methods: We present two illustrative cases of the technique of stacking three PEEK cages around a fibula strut graft (group 1). Cases were compared to cohort of 15 patients (group 2) with 3 level anterior cervical discectomy and fusion (ACDF).

Results: Average age and BMI for group 1 was 52 years and $36.9 \mathrm{~kg} / \mathrm{m}^{2}$ compared to group 2 average age 59 years and BMI $25 \mathrm{~kg} / \mathrm{m}^{2}, \mathrm{p}=0.53$ and 0.21 respectively. Mean preop VAS neck score in group 1 of 8.5 compared to group 2 of $6.5, p=0.08$. Preop NDI in group 1 of 52 compared to group 2 of $43.4, p=0.355$. There was no statistical difference in post op outcomes at 6,12 and 24 months, $p>0.05$. There was no evidence of construct failure, subsidence, or focal kyphosis in either group which was demonstrated on CT radiograph.

Conclusion: We have illustrated technique of combining the strength of a fibula strut graft for achieving fusion and PEEK cages for stability and favourable modulus of elasticity of that the vertebrae. The assessment of outcome scores demonstrated similar efficacy of treatment. There were no reported major complications in either group. Further application of this approach is the next steps to establish this technique's efficacy.

Keywords: Corpectomy defect; Stacking multiple PEEK cage; technical note

\section{Introduction}

Fibula strut grafts have a proven history of effectiveness for anterior cervical corpectomies but are inherently vulnerable to complications such as early or late fracture, dislodgement, displacement, telescoping into the vertebral body, or non-union [1-4]. The settling and resultant segmental kyphosis after multi-level anterior cervical reconstruction has also been documented [5-7]. The risk of graft migration, displacement, or fracture is more likely with more vertebral bodies removed and longer grafts [3,7] and with corpectomies involving a fusion ending at the C7 vertebral body [6]. Newer interbody stabilization options include polyetherketone (PEEK) which has the advantage of greater endplate coverage leading to a more stable construct, and similar modulus of elasticity as bone [8]. However, PEEK cages require separate graft material for interbody fusion. Other options include metal expandable cages [9-11] but these can be bulky, risk adjacent body fracture, and have limited room for bone graft; and therefore, do not provide the most ideal biologic environment [12]. Stacking PEEK cages end to end over a fibular allograft is a novel method to fill the corpectomy void in order to achieve a modulus of elasticity similar to bone, accommodate bone graft substrate, and provide appropriate structural support and height restoration. Here we describe technique steps to stack PEEK cages around fibula strut grafts during ACDF.

\section{Materials and Methods}

\section{Illustrative case 1}

A 48 year old man referred with a massive C5- 6 herniated disc and Modic endplate changes [13] on magnetic resonance imaging (MRI) and 5-/5 weakness and diminished sensation in the C6 distribution
(Figure 1). This patient's radiculomyelopathy was attributed to the C5-6 herniated disc, and subsequently he underwent ACDF. Six weeks postoperatively the patient still had residual pain and bilateral arm numbness. Repeat MRI illustrated improvement but computed tomography (CT) showed large posterior osteophytes causing residual stenosis at the level of the C5 and C6 endplates along with functional compression at $\mathrm{C} 3-\mathrm{C} 4$. He underwent revision $\mathrm{C} 5$ corpectomy and C3-4 ACDF

\section{Operative technique}

Patient is placed supine under general anesthesia with extension of neck. A transverse anterior incision is made at C5 operative level. Exposure of anterior cervical spine using standard technique, and longus colli muscle elevated laterally. Identification of disc space was performed using a probe and fluoroscopy. Distraction pins were then placed in the bodies of $\mathrm{C} 4$ and C6. Total discectomy was performed at C4-5, 5-6. A Leksell was then used to perform corpectomy on C5

${ }^{*}$ Corresponding author: Kingsley R. Chin, Affiliate Professor, Charles E. Schmidt College of Medicine at Florida Atlantic University, Attending Orthopedic Spine Surgeon, Less Exposure Surgical Specialists Institute Surgery, 1100 W. Oakland Park Blvd. Suite \#3 Fort Lauderdale, FL, 33311, USA, Tel: 954-640-6010; Fax: 855411-4647; E-mail: kingsleychin@gmail.com

Received June 28, 2015; Accepted July 30, 2015; Published August 01, 2015

Citation: Chin KR, Pencle FJR, Seale JA, Jethanandani RG, Hothem EA, et al. (2015) New Approach to Filling a Corpectomy Defect by Stacking Multiple Peek Cages around a Fibula Strut Graft: A Technical Note. J Spine 4: 242. doi:10.4172/21657939.1000242

Copyright: $\odot 2015$ Chin KR, et al. This is an open-access article distributed under the terms of the Creative Commons Attribution License, which permits unrestricted use, distribution, and reproduction in any medium, provided the original author and source are credited. 


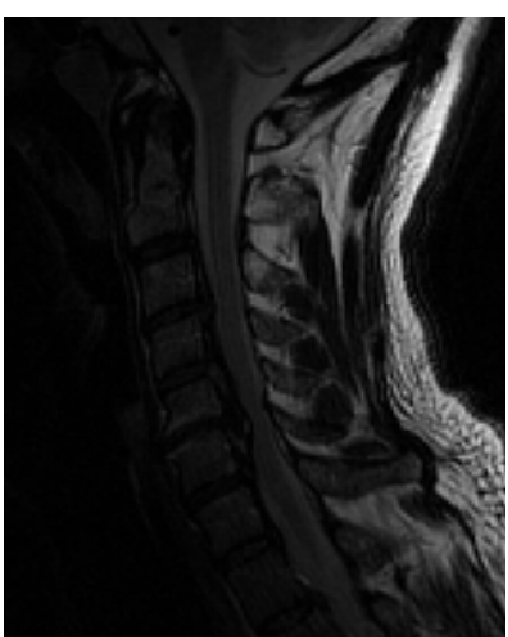

Figure 1: Preoperative sagittal MRI patient 1.

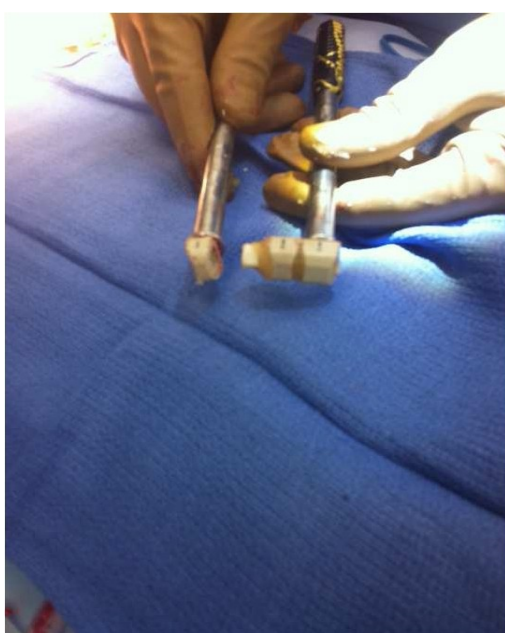

Figure 2: Intraoperative photo showing end of fibula graft with remainder within the cages patient 1 .

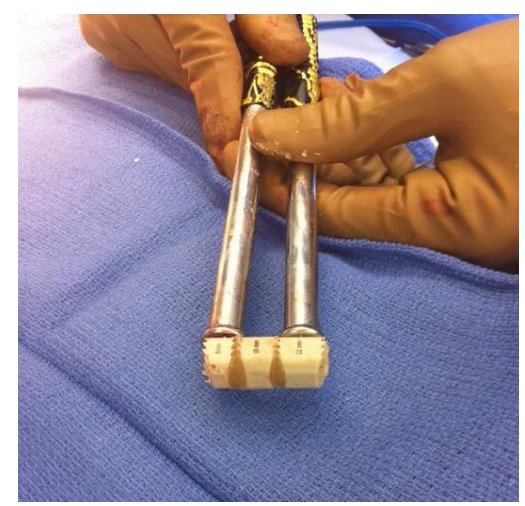

Figure 3: Three PEEK cages stacked around the fibula strut graft with DBM packed in the spaces - patient 1.

vertebral body and Kerrison ronguers used to complete corpectomy. We measured a $30 \mathrm{~mm}$ long fibula strut graft. The fibula strut allograft was fashioned and cut in half length wise and placed through the inside of three PEEK cages for a total length of $30 \mathrm{~mm}(12 \mathrm{~mm}, 10 \mathrm{~mm}, 8 \mathrm{~mm})$ (Figures 2 and 3 ). The remaining space inside the PEEK cages was filled with autograft and DBM. The combined cages and fibula strut graft were placed in the trough and distraction pins removed to allow the C4 and C6 vertebrae to collapse around the construct. Demineralized bone matrix (DBM) and autograft corpectomized bone were placed alongside the fibula strut graft. DBM was placed in front of the cages and behind the plate at all levels. Disc space was then prepared in standard fashion for C3-4. An $8 \mathrm{~mm}$ cage (Eminent Spine, Texas) filled with autograft bone and DBM was placed at C3-4 and A $60 \mathrm{~mm}$ cervical plate with appropriate lordotic curve was placed with screws in C3, C4, and C6. (SpineFrontier Inc., Indus Invue Plate).

\section{Illustrative case 2}

Our second case presentation is of a 55 year old female with a traumatic fracture-dislocation of C6-7 and a massive herniated disc as well as C5-6 herniated disc (Figure 4). After performing a 2 level discectomy and corpectomy using similar operative technique, the corpectomy trough was prepared. The defect measured $23 \mathrm{~mm}$ so on $7 \mathrm{~mm}$ and two $8 \mathrm{~mm}$ cages were used. A piece of fibular allograft was cut to $23 \mathrm{~mm}$ shaved down to fit inside the cages. After packing with $\mathrm{DBM}$, a $37 \mathrm{~mm}$ plate was contoured and secured. The patient did well post operatively with maintained neurologic status and uneventful progression to resumption of normal activities at 4 months.

The outcomes of these two patients (group 1) was compared to cohort of 15 patients (group 2) were anterior cervical decompression and fusion was performed using PEEK cages at three consecutive levels. Outcomes included VAS neck scores, NDI and fusion rates.

Statistical analysis was performed using SPSS v.22 IBM Corp, New York.

\section{Results}

Average age and BMI for group 1 was 52 years and $36.9 \mathrm{~kg} / \mathrm{m}^{2}$ compared to group 2 average age 59 years and BMI $25 \mathrm{~kg} / \mathrm{m}^{2}, \mathrm{p}=0.53$ and 0.21 respectively. Mean preop VAS neck score in group 1 of 8.5 compared to group 2 of $6.5, \mathrm{p}=0.08$. Preop NDI in group 1 of 52 compared to group 2 of $43.4, \mathrm{p}=0.355$. Post op VAS and NDI scores were assessed at 6 month; 12 month and 24 month follow up. There was no difference noted in outcomes (Tables 1 and 2).

\section{Follow up}

The most common complication reported in both groups included residual pain and tingling. At one year our first patient experienced mild residual complaints of neck pain, numbness and tingling but was

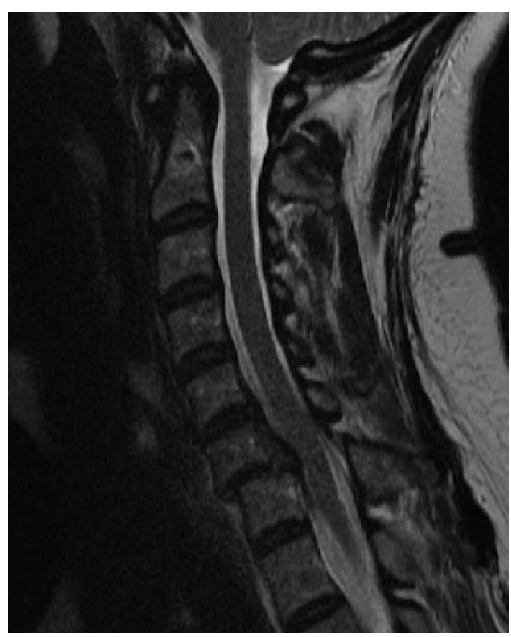

Figure 4: Preoperative sagittal MRI patient 2. 
Citation: Chin KR, Pencle FJR, Seale JA, Jethanandani RG, Hothem EA, et al. (2015) New Approach to Filling a Corpectomy Defect by Stacking Multiple Peek Cages around a Fibula Strut Graft: A Technical Note. J Spine 4: 242.doi:10.4172/21657939.1000242

Page 3 of 4

\begin{tabular}{|c|c|c|c|}
\hline Post op VAS & Group 1 & Group 2 & P values \\
\hline 6 month & 5 & 5.8 & 0.08 \\
\hline 12 month & 3.5 & 4.5 & 0.48 \\
\hline 24 month & 4 & 3.3 & 0.86 \\
\hline
\end{tabular}

Table 1: Post-operative visual analog scale (VAS) scores.

\begin{tabular}{|c|c|c|c|}
\hline Post op NDI & Group 1 & Group 2 & P values \\
\hline 6 month & 48 & 39.2 & 0.792 \\
\hline 12 month & 30 & 32.3 & 0.142 \\
\hline 24 month & 23 & 27.8 & 0.491 \\
\hline
\end{tabular}

Table 2: Post-operative neck disability index (NDI) scores.

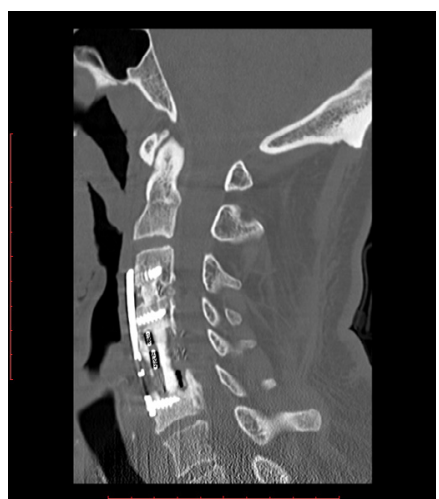

Figure 5A: Postoperative sagittal CT radiograph of patient 1 with stacked PEEK cages in situ.

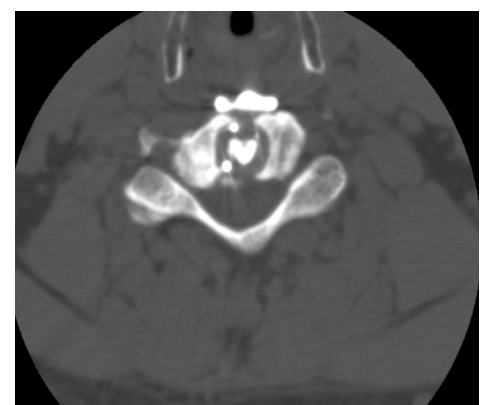

Figure 5B: Postoperative axial CT radiograph of patient 1.

much improved overall. Our 2nd patient only noted residual pain although markedly improved.

Fusion was achieved at 12 months in 1st patient, 6 months in 2nd patient in group 1. At two year follow up CT showed evidence of graft consolidation consistent with fusion in 1st patient (Figure $5 \mathrm{~A}$ and $5 \mathrm{~B}$ ) and 2 nd patient Figure $6 \mathrm{~A}$ and $6 \mathrm{~B}$. The plate and screws were stably fixed. There was no evidence of construct failure, subsidence, or focal kyphosis. Comparing fusion rate of group 2 fusion was achieved as early as 6 months. At two years follow up CT showed evidence of graft consolidation (Figure 7A and 7B).

\section{Discussion}

Although fibula strut grafts are historically an effective option for anterior cervical corpectomy, they are vulnerable to complications as the number of levels decompressed increases $[1,3,6,7,14]$. Associated donor site morbidity is an additional consideration [15,16]. Patients often have compliance difficulties with cervical bracing when fibula strut grafts are used without plating. Patients with buttress plating of fibular allografts may be at increased risk of graft failure. Patients with a smoking history may be at further risk for unfavorable outcomes without a stable fibula strut graft after corpectomy

PEEK cages have good biomechanical characteristics and a comparable elastic coefficient to that of human bone. ACDF with a PEEK cage has shown good clinical results for single level cervical disorders [17-21]. Stacking multiple cages provides adequate height restoration in a modular construct to fill corpectomy defect with the ease of implant placement. This is a much more cost efficient method than expensive expandable cages. Filling the PEEK cages with fibular allograft strips results in a stable construct by providing an internal frame that prevents the cages from becoming dissociated. The end result of this technique is a corpectomy construct that has a similar elastic coefficient to bone, stability of an expandable cage, modularity to fit the corpectomy defect in a stable and convenient construct.

Our study has demonstrated no statistical difference in outcomes between the patients who were treated with stacked PEEK cage and fibula strut technique compared to patients who had three level ACDF performed. There were no readmissions in either groups but patients noted residual pain although improved. The authors note the limitations of being a small sample with a matched cohort of three levels ACDF.

We have illustrated a new technique in which we combined the favourable attributes of a fibula strut allograft for achieving fusion and PEEK cages for stability and similar modulus of elasticity to that of the vertebrae. As these were both fibula allographs there was no associated

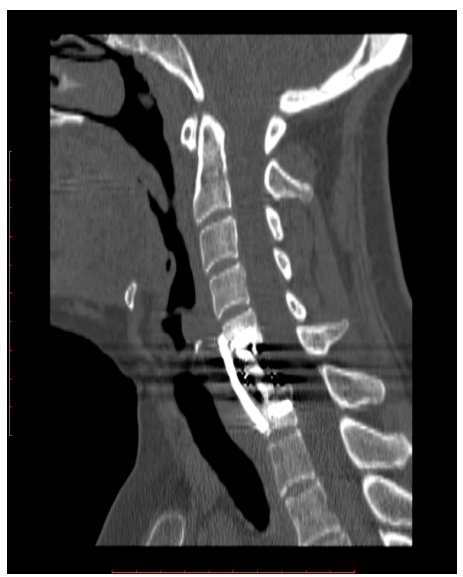

Figure 6A: Postoperative sagittal CT radiograph of patient 2 with stacked PEEK cages in situ. Indication for surgery was a fracture-dislocation C6-7 and herniated nucleus pulposus C5-6 and C6-7.

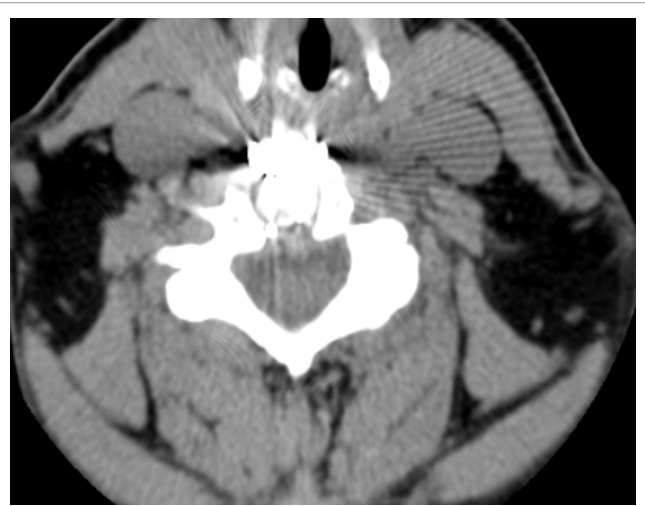

Figure 6B: Postoperative axial CT radiograph of patient 2. 
Citation: Chin KR, Pencle FJR, Seale JA, Jethanandani RG, Hothem EA, et al. (2015) New Approach to Filling a Corpectomy Defect by Stacking Multiple Peek Cages around a Fibula Strut Graft: A Technical Note. J Spine 4: 242.doi:10.4172/21657939.1000242

Page 4 of 4

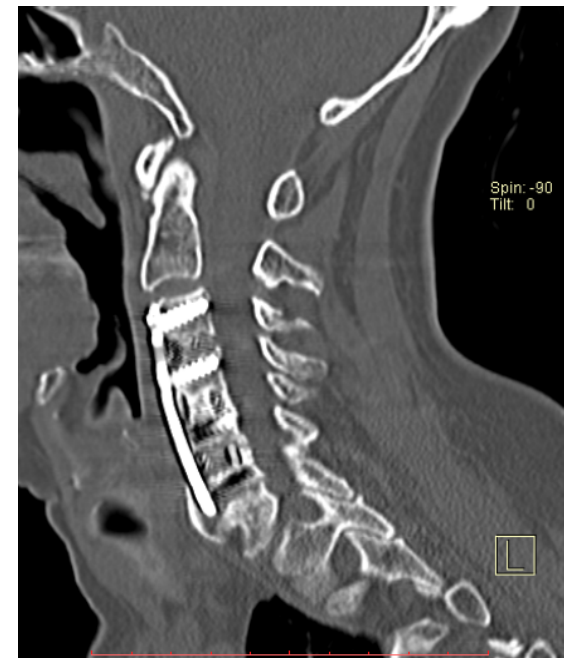

Figure 7A: Postoperative sagittal CT radiograph demonstrating fusion.

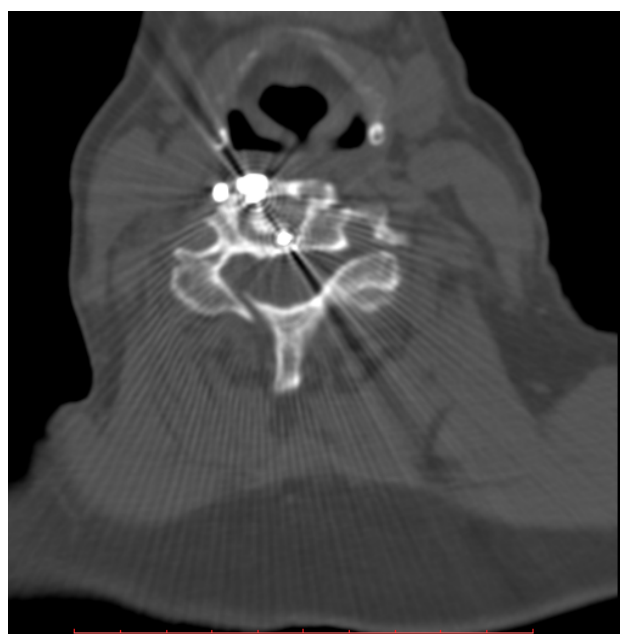

Figure 7B: Postoperative axial CT radiograph demonstrating fusion.

donor site morbidity. The benefits of this technique are intuitive, but further experience and technological investigation with larger sample sizes into stackable PEEK cages combined with osteobiologics are needed to advance this technique's options in the cervical and lumbar spine.

\section{References}

1. Thongtrangan I, Balabhadra RSV, Kim DH (2003) Management of strut graft failure in anterior cervical spine surgery. Neurosurgical focus 15: E4.

2. Emery SE, Bohlman HH, Bolesta MJ, Jones PK (1998) Anterior cervical decompression and arthrodesis for the treatment of cervical spondylotic myelopathy. Two to seventeen-year follow-up. The Journal of bone and joint surgery. American 80: 941-951.

3. Macdonald RL, Fehlings MG, Tator CH, Lozano A, Fleming JR, et al. (1997)
Multilevel anterior cervical corpectomy and fibular allograft fusion for cervical myelopathy. Journal of neurosurgery, 86: 990-997.

4. Fernyhough JC, White JI, LaRocca H (1991) Fusion rates in multilevel cervica spondylosis comparing allograft fibula with autograft fibula in 126 patients. Spine 16: S561-564.

5. Hughes SS, Pringle T, Phillips F, Emery S (2006) Settling of fibula strut grafts following multilevel anterior cervical corpectomy: a radiographic evaluation. Spine 31: 1911-1915.

6. Wang JC, Hart RA, Emery SE, Bohlman HH (2003) Graft migration or displacement after multilevel cervical corpectomy and strut grafting. Spine 28 : 1016-1021.

7. Hanks SE and Kang JD (2004) Late stress fracture of a well-incorporated autologous fibula strut graft in the cervical spine: a case report. Journal of spinal disorders \& techniques 17: 526-30.

8. Song KJ, Kim GH, Choi BY (2011) Efficacy of PEEK cages and plate augmentation in three-level anterior cervical fusion of elderly patients. Clinics in orthopedic surgery $3:$ 9-15.

9. Chou D, Lu DC, Weinstein P, Ames CP (2008) Adjacent-level vertebral body fractures after expandable cage reconstruction. Journal of neurosurgery. Spine 8: 584-588.

10. Auguste KI, Chin C, Acosta FL, Ames CP (2006) Expandable cylindrical cages in the cervical spine: a review of 22 cases. Journal of neurosurgery Spine 4: 285-291.

11. Alfieri A, Gazzeri R, Neroni M, Fiore C, Galarza M, et al. (2011) Anterio expandable cylindrical cage reconstruction after cervical spinal metastasis resection. Clinical neurology and neurosurgery 113: 914-917.

12. Kandziora F, Pflugmacher R, Schaefer J, Scholz M, Ludwig K, et al. (2003) Biomechanical comparison of expandable cages for vertebral body replacement in the cervical spine. Journal of neurosurgery 1: 91-97.

13. Rahme R and Moussa R (2008) The modic vertebral endplate and marrow changes: pathologic significance and relation to low back pain and segmental instability of the lumbar spine. AJNR American journal of neuroradiology 29: 838-842.

14. Kojima T, Waga S, Kubo Y, Kanamaru K, Shimosaka S,et al. (1989) Anterio cervical vertebrectomy and interbody fusion for multi-level spondylosis and ossification of the posterior longitudinal ligament. Neurosurgery 24: 864-872.

15. Nassr A, Khan MH, Ali MH, Espiritu MT, Hanks SE, et al. (2009) Donorsite complications of autogenous nonvascularized fibula strut graft harvest for anterior cervical corpectomy and fusion surgery: experience with 163 consecutive cases. The spine journal : official journal of the North American Spine Society 9: 893-898.

16. Malloy KM and Hilibrand AS (2002) Autograft versus allograft in degenerative cervical disease. Clinical orthopaedics and related research 394: 27-38.

17. Liao JC, Niu CC, Chen WJ, Chen LH (2008) Polyetheretherketone (PEEK) cage filled with cancellous allograft in anterior cervical discectomy and fusion. International orthopaedics 32: 643-648.

18. Cho DY, Liau WR, Lee WY, Liu JT, Chiu CL, et al. (2002) Preliminary experience using a polyetheretherketone (PEEK) cage in the treatment of cervical disc disease. Neurosurgery 51: 1343-1349.

19. Kulkarni AG, Hee HT, Wong HK (2007) Solis cage (PEEK) for anterior cervical fusion: preliminary radiological results with emphasis on fusion and subsidence. The spine journal : official journal of the North American Spine Society 7: 205-209.

20. Song KJ and Lee KB (2006) A preliminary study of the use of cage and plating for single-segment fusion in degenerative cervical spine disease. Journal of clinical neuroscience : official journal of the Neurosurgical Society of Australasia 13: 181-187.

21. Dufour T, Huppert J, Louis C, Beaurain J, Stecken J, et al. (2010) Radiologica analysis of 37 segments in cervical spine implanted with a peek stand-alone device, with at least one year follow-up. British journal of neurosurgery 24: 633-640. 